\title{
ЕКАТЕРИНА ПАСТЕРНАК
}

(iD) https://orcid.org/0000-0001-6997-6632

Московский государственный университет имени М. В. Ломоносова

Институт мировой культуры

119234 Москва

Ленинские горы, д. 1, стр. 51

katrusia95@mail.ru

\section{«И ЧРЕЗ ПРИМЕР ЯВИЛ СЕЙ СВОЙ»: О НЕКОТОРЫХ ОСОБЕННОСТЯХ МЕТРИКО-СТРОФИЧЕСКОГО РЕПЕРТУАРА ПОЗДНЕГО ДЕРЖАВИНА ${ }^{1}$}

\author{
ON SOME FEATURES OF DERZHAVIN'S \\ LATE METRIC-STANZAIC REPERTOIRE ${ }^{2}$
}

The paper discusses versification features of the texts that make up the fifth volume of Sochineniya Derzhavina [The Works of Derzhavin], the last book compiled by the poet during his lifetime. These 57 poems have rarely been an object of scholarly attention and have not previously been analysed in terms of versification as a corpus.

The author of the article has compiled a metric-stanzaic directory for this volume. An analysis of the material indexed this way shows that most of the poems are written in one kind of stanza. Only "Tseleniye Saula" [The Cure of Saul], a compositional centre of the collection, is written in various types of stanzas. Another work pivotal for the book, "Gimn liro-epichesky" [The Lyric-epic hymn], is written in complex Pindaric triads. Among other stanzas, the poet shows a predilection for the 8- and 6-line strophes; many poems are also written in the odic stanza (and all the odic stanzas are cast in the 4-foot iambics, traditional for them) or use variations thereof. The quatrain, one of the most popular stanzas in Russian poetry, does not occur very often in the book. Moreover, none of the quatrains is written in a 4 -foot iamb - unlike the stanzas with 8 lines, more than $70 \%$ of which employ this metre. It is interesting that Derzhavin does not give preference to the rhythmic scheme of the 4-foot iamb, which is considered characteristic of his earlier poetry (with the first and fourth feet strong, second and third feet weak).

The poet often employs more stresses than required by a given metre, and they can have different functions. For example, in the poem "Problesk" [A Glimpse] it is connected with the plot of

${ }^{1}$ Исследование выполнено за счет гранта Российского научного фонда (проект № 19-78-10132) в Институте мировой культуры Московского государственного университета имени М. В. Ломоносова.

${ }^{2}$ This article results from the research project based at the Institute for World Culture of Lomonosov Moscow State University (MSU) and supported by the Russian Scientist Foundation grant 19-78-10132. 
the poem: the lines which speak of the difficulty of walking a path contain a high number of such "excess" stresses, through which the reader must "wade". In some cases, a variable reading is possible (and, accordingly, the decision on the presence or absence of an extra stress) - where neither of two points of view contradicts the text, the reading depends on the arrangement of logical stresses. Transaccentuation, on the other hand, is not very common in Derzavin's fifth volume.

There are several instances of poems written in metres that must have seemed to Derzhavin similar to the ones used in the Antiquity. The most interesting of these is "Poligimnii" [To Polyhymnia], the poem that closes the collection. It is dedicated to the theme of the poet and poetry and as if serves demonstrating Derzhavin's own skills. He seems to be stylising the meter to resemble "antique" ones (although the result is unlike any of the meters traditionally employed in Russian poetry with a view to imitating antique metrics). The choice of the stanzas is also unusual - they consist of 7 lines, with the first four lines in each rhymed (and the type of line endings varies throughout the poem), while the latter three are left unrhymed. The distribution of stresses in the line endings of the blank verses used in the last stanza occurs only once in the poem. This stanza, which is the semantic core of the poem and which closes the collection with the final line "I will be immortal, I will!", was apparently written with intentional sophistication.

In general, the analysis of the metric-stanzaic repertoire of the late Derzhavin makes it possible to see the poet as a real old master who pays attention to versification issues, avoids monotony, looks for new metrical patterns, and composes his collection skilfully - also from the point of view of versification features of the texts.

Keywords: Derzhavin, versification, metric-stanzaic repertoire, composition, "Poligimnii" [To Polyhymnia].

В статье рассматриваются версификационные особенности текстов, составляющих пятый том Сочинений Державина, последней книги, составленной поэтом при жизни. 57 стихотворений редко становились объектом внимания исследователей и ранее не были проанализированы с точки зрения версификации как корпус.

Анализ составленного автором статьи метрико-строфического справочника этого тома показывает, что большинство стихотворений написано каким-либо одним видом строфы. Разнотипными строфами написано только Целение Саула, один из композиционных центров сборника. Другое произведение, также являющееся одним из самых важных в книге, Гимн тиро-эпический..., написано сложными пиндарическими триадами. Среди других строф поэт любит 8-стишия и 6-стишия, многие стихотворения также написаны одической строфой (причем все одические строфы написаны традиционным для них Я4) или вариациями на ее тему. Катрен же, одна из самых популярных строф в русской поэзии, встречается в книге не очень часто, причем ни один из них не написан Я4 - в отличие от 8-стиший, более $70 \%$ которых написано именно им. Интересно, что Державин не отдает предпочтение той ритмической схеме Я4, которая считается традиционной для его более ранней лирики (ударные 1-я и 4-я стопы, между ними - пиррихии).

Поэт часто использует сверхсхемные ударения, причем они могут играть разную роль. К примеру, в стихотворении Проблеск это связано с сюжетом стихотворения: стихи, в которых речь идет о трудности прохождения пути, содержат массу сверхсхемных ударений, через которые должен «пробираться» читатель. В некоторых случаях возможна вариативность прочтения (и, соответственно, решение о наличии / отсутствии сверхсхемного ударения), поскольку обе точки зрения не противоречат тексту, прочтение зависит от расстановки логических ударений. Переакцентуация же не очень часто встречается в 5-м томе.

Несколько раз Державин пишет стихотворения размерами, которые кажутся ему похожими на античные. Наиболее интересным из них является Полигимнии - стихотворение, которое завершает сборник. Оно посвящено теме поэта и поэзии и демонстрирует мастерство самого Державина. Он как будто стилизует размер под «античный» (при этом то, что у него получилось, не похоже ни на один из тех размеров, с помощью которых в русской поэзии 
принято стилизовать античные размеры). Необычен и выбор строф - это 7-стишия, первые четыре стиха в каждом 7-стишии зарифмованы (причём рисунок клаузул на протяжении стихотворения меняется), следующие три - нет. Схема холостых стихов, использованная в последней строфе, встречается в этом стихотворении только один раз. Эта строфа, являющаяся смысловым центром стихотворения и ставящая точку в сборнике финальным стихом «Буду я, буду бессмертен!», по-видимому, специально написана изощренно.

В целом можно сказать, что анализ метрико-строфического репертуара позднего Державина позволяет увидеть поэта как настоящего старого мастера, который помнит о версификационных вопросах, не становится однообразным, ищет новые размеры, умело выстраивает композицию своего сборника - в том числе с точки зрения версификационных особенностей текстов.

Ключевые слова: Державин, версификация, метрико-строфический репертуар, композиция, Полигимнии.

Пятый том Сочинений Державина этом при жизни, традиционно считается малоудачной частью его наследия. Эти тексты редко становились объектом внимания исследователей - показателен фрагмент из Ключа к сочинениям Державина Н. Ф. Остолопова, прижизненного комментатора произведений поэта (в Ключе анализируются стихотворения, написанные по 1805 г.):

Не знаю, находится ли у кого-нибудь продолжение подобных объяснений; впрочем, можно сказать, что последующие сочинения Державина не имеют в оных такой надобности, как здесь помещенные, ибо по большей части писаны ясно и для всякого понятно 4 .

Парадоксально, но за двести лет, которые прошли с момента публикации этого текста, взгляд на позднее наследие Державина в целом не изменился. В дальнейших изданиях поэта эту часть корпуса его произведений обходят стороной как малоценную и не представляющую интереса. Версификационные особенности стихотворений позднего Державина также не были проанализированы настолько внимательно, насколько они этого заслуживают. Рассмотрение метрико-строфического репертуара пятого тома Сочинений позволяет отметить следующие черты.

Абсолютное большинство стихотворений написано каким-либо одним видом строфы. Поэт выбирает его в начале произведения и использует на протяжении всего стихотворения. Небольшие по объему тексты, лишенные строфической сегментации (в зависимости от определения строфы,

${ }^{3}$ Г. Р. Державин, Сочинения Державина: в 5 ч. Санкт-Петербург: В Тип. В. Плавильщикова 1816, ч. 5.

${ }^{4}$ Н. Ф. Остолопов, Ключ к сочинениям Державина: С кратким описанием жизни сего знаменитого поэта, Санкт-Петербург: В тип. Ив. Глазунова 1822, с. 94-95. 
которого придерживается исследователь, он может считать их одной строфой или рассматривать как астрофические), встречаются нечасто.

Только одно произведение - Целение Саула, вместе с Гимном лироэпическим находящееся в композиционном и смысловом центре сборника, состоит из разнотипных строф. При написании оратории Державин ориентировался на sacred ode, священную оду английского философа и проповедника Дж. Брауна The Cure of Saul 5 . Как и Браун, Державин пишет Целение Саула разнообразными строфами, однако это не точное копирование тех строф, которые были у его предшественника, а заимствование самой идеи написания произведения с использованием разных строф. Например, у Брауна в 1-й строфе рифмовка ааББвгвгддЕжжЕ, в 3-й - аббввагдгдеежзжзиий йклкммл, в 5-й строфе - только парные рифмы. У Державина в 1-й строфе - АбАбвГГвДДеЖЖззИИеЙЙккккЛЛмм, в 8-й - ааББвГвГдЕжждЕззии, 14-я строфа содержит только парные рифмы. Кроме того, в отличие от Брауна, Державин использует разные размеры. В первую очередь это ямб, причем в некоторых строфах, например в 1-й, он вольный; в некоторых, например в 3-й, заметна логика в чередовании стихов с разным количеством стоп; некоторые же, например 6-я, целиком написаны одним видом ямба. Вместе с тем в стихотворении встречаются анапест (Ан4), хорей (X4), дактиль (в двух строфах - Дк2, где часть строк похожа на хореямб, здесь есть переменная (нулевая-односложная) анакруса, из-за чего часть стихов также похожа на Амф2, и осложнение схемы дополнительными ударениями, еще в одной строфе - Дк4). Целение Саула - самое разнообразное в строфическом плане произведение пятого тома.

Упомянутый Гимн также написан с использованием причудливых строф. Он состоит из 17 строф, каждая из которых содержит три части: две части по 10 строк Я4, чья схема отдаленно напоминает схему одической строфы (аББаВВггДД), и одна часть из 18 строк, написанная необычным размером: Я4-4-4-3-4-3-6-4-3-3-4-4-5-5-4-5-4-3 (формальное строение строф строго выдерживается; только один раз, во второй части 14-й строфы, 5-й стих содержит лишнюю стопу: «Доколь Москва, Непрядва и Полтава» ${ }^{6}$ ). М. Л. Гаспаров называет такое сложное строфическое образование «пиндарической триадой» и отмечает, что к пиндарической строфике и вообще

${ }^{5}$ J. Brown, The Cure of Saul, a sacred ode, London: L. Davis and C. Reymers 1763. Это отмечено М. Г. Альтшуллером в единственной статье, полностью посвященной оратории: М. Г. Альтшуллер, Оратория «Целение Саула» в системе поздней лирики Державина, [в:] XVIII век, сб. 21: Памяти Павла Наумовича Беркова (1896-1969), Санкт-Петербург: Наука 1999, с. 269-281.

${ }^{6}$ Г. Р. Державин, Сочинения..., с. 135; см. также: В. Л. Коровин, Державин и 1812 год: О смысле и композиции «Гимна тироэпического на прогнание франиузов из Отечества», «Известия Российской академии наук. Серия литературы и языка» 2012, т. 71, № 6, с. 47-48. 
к наследию Пиндара Державин обращался ранее. Безусловно, и для оратории, и для Гимна поэт выбирает необычные строфы сознательно. Строфику в книге можно назвать продуманной, однако обычно она гораздо менее вычурна.

Чаще всего у Державина встречаются два типа строф. Во-первых, это восьмистишия, которые из-за рифмовки как бы разбиваются на катрены (12 случаев, когда встречается строфа АбАбВгВг, 5 - АбАбВВгг, 2 - аБ БаВВгг). Только в одном случае все 8-стишные строфы связаны двумя цепочками рифм АбАббАбА между собой и с последним катреном бАбА. Во-вторых, это одическая строфа (9 случаев - АбАбВВгДДг). Встречаются также вариации на тему одической строфы, например, аББаВВггДД (с одической строфой это 10-стишие роднят наличие парной женской рифмы в середине строфы и как бы переставленная из середины в конец парная рифма в последних четырех строках) или АбАбВВгДгеДе (7 строк повторяют схему одической строфы, 5 - новы), АбАбВгВгДееД (об одической строфе напоминают сочетание перекрестных женских и мужских рифм в первых четырех строках, а также сочетание кольцевой и парной рифмовки в последних четырех строках, правда, в них клаузулы зеркально отражаются по сравнению с классической схемой), АбАбВгВгДДеЖЖе (первые четыре стиха как бы продублированы, в последних четырех стихах зеркально меняются типы клаузул; это попытка Державина написать сонет, напоминающий французский).

Встречаются также шестистишия (АбАбВВ - 1 случай, абабвв - 2 случая), причем чаще они оканчиваются холостыми стихами (АбАбХх - 6 случаев, аББаХx - 1 случай). Считается, что подобную форму Державин увидел в немецких стихотворениях, где довольно часто встречается стих-вайзе 8 6- и 8-стишия, «распадающиеся» на две части, впоследствии станут очень распространенными (эту форму особенно любил Ф. И. Тютчев).

Интересно, что классический катрен АбАб, будучи самой употребительной строфой в русской поэзии силлабо-тонического периода, встречается в пятом томе не так уж часто. Катренами написаны только три стихотворения, еще в одном они используются наряду с другой строфой (правда, одно из этих произведений - Царь-Девица - весьма объемно: в нем 52 катрена). Вместе с тем Державин трижды использует катрены в белых стихах: только с женскими клаузулами; с чередованием ХxXx; с неупорядоченным чередованием клаузул.

Весьма необычны строфы, полностью или частично состоящие из холостых стихов. В основном поэт просто чередует виды клаузул, чтобы добиться

\footnotetext{
${ }^{7}$ М. Л. Гаспаров, Очерк истории русского стиха, Москва: Фортуна Лимитед 2000, с. 106.

${ }^{8}$ Там же, с. 101-102.
} 


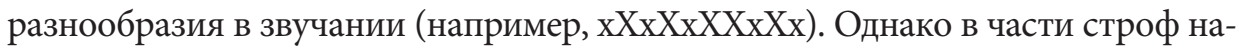
блюдается строгая последовательность чередования стихов с разными клаузулами, например, ХaXaXxXx, xxXaXaXx, XXxXx, необычная строфа хXХаББа.

В одном случае строфа состоит из последовательности парных рифм (часть одинаковых по структуре строф в Гимне).

Несколько раз встречается довольно прихотливая рифмовка: последние строки одной строфы как бы остаются холостыми, однако потом находят рифму в следующей строфе, т. е. на самом деле это скользящая рифма. Это АбАбВг ДеДеВг.., аБаБвГвГдЕ жЗжЗиЙиЙдЕ..., АбАбВгВгД ЕжЕжЗиЗиД. Благодаря такому сравнительно редкому приему, с одной стороны, сначала нарушается рифменное ожидание, с другой - впоследствии создается эффект большей «связанности», «сцепленности» строф по сравнению с «обычными» строфами, в которых рифма не выходит за пределы одной строфы.

Таким образом, говоря о видах строф, используемых поэтом в книге, следует отметить, что строфический репертуар примерно наполовину состоит из «обычных», повторяющихся из стихотворения в стихотворение строф, в оставшейся же части много как вариаций на тему этих строф, так и новых, необычных строф. В отличие от произведений более раннего периода, в пятом томе редко используются какие-либо изощренные строфы. Многое из того, что выглядит необычным, Державин придумал ранее (например, связывать несколько объемных строф рифмой, исходящей из конца одной строфы в конец другой). Ничего, что могло бы сравниться, например, со строфикой Фонаря, в пятом томе нет, однако нельзя утверждать, что строфы Державина становятся «обычными». Заметно его внимание к версификации и при анализе композиции. Например, два текста, находящиеся в композиционном и смысловом центре сборника - оратория Целение Cayла и Гимн - написаны сложными, необычными строфами.

Если же посмотреть на то, как выбор строфы соотносится с выбором размера, получится следующая картина.

Сначала рассмотрим повторяющиеся полностью рифмованные катрены. Для них Державин выбирает не самые обычные размеры. Ни один катрен не написан Я4 (самая типичная строфа в русской поэзии силлаботонического периода - АбАб, Я4). Дважды встречается Х4, один раз - X5, один раз - строфа Я6-6-6-4 (александрийский стих). Абсолютное большинство таких строф написано X4 за счет объемного произведения Царь-Девииа (52 строфы из 73,71\%).

Шестистишия также пишутся разнообразными размерами. Это и более предсказуемые X3, X4 и Я4, и Я6, и более изощренные и необычно звучащие Я5-3-5-3-4-3 и Я6-5-5-5-6-3, и даже Амф2. Из 72 строф только 1/4 написана Я4, остальное приходится на другие размеры. 
Гораздо более предсказуемы восьмистишия. Здесь безусловный лидер - Я4. 133 строфы из 186 (71,51\%) написаны именно им; 5,91\% - Х4; 5,38\% - X5; 3,23\% - Х3. Остальные строфы написаны другими размерами. Особенно интересно то, что здесь встречается дактиль, которым написано целых девять строф.

Наконец, самой предсказуемой является одическая строфа. Абсолютно все одические строфы написаны Я4, как им и подобает в классическом случае. Только в одном случае последний стих каждой из семи одических строф укорочен и написан ЯЗ.

Если посмотреть на необычные, неповторяющиеся строфы (например, АбАбВгВгДееД или аББаХ), можно увидеть, что почти все они написаны Х4, Я3 или Я4. Необычность строф сочетается с «классическими», обычными размерами. Только один раз встречается Я6, кроме того, в Полигимнии Державин как будто изобретает новый размер, экспериментируя с русификацией античных размеров, однако у него получается подобие тактовика.

Похожую закономерность можно увидеть при анализе белых стихов. Здесь наблюдаются две тенденции. С одной стороны, большинство таких стихотворений написано Я4, встречается также X3 и Я3. С другой стороны, Державин пробует писать размерами, имитирующими античные, что часто сочетается с темой произведения. Безусловно, наибольшей изощренности он достигает в Полигимнии - версификационные особенности этого стихотворения будут рассмотрены далее.

Некоторые вопросы, связанные с метрикой в пятом томе, также заслуживают отдельного рассмотрения.

Главная тенденция, которая бросается в глаза, - несоблюдение Державиным той схемы Я4, которая считается традиционной для его лирики в предыдущие периоды. Согласно подсчетам Гаспарова, наиболее употребительной была схема, в которой ударными являются 1-я и 4-я стопы, a 2-я и 3-я безударны. Эта точка зрения уже подвергалась критике9. Анализ метрики пятого тома полностью подтверждает этот вывод: никакой тенденции к использованию именно этой модели Я4 выявить не удалось. Напротив, Державин весьма изобретателен в моделях Я4. У него можно найти как схемы, в которых каждому метрическому ударению будет соответствовать фактическое ударение (интересно, что таких «архаичных» схем будет особенно много в Гимне), так и гораздо более редкие схемы, например, те, в которых будут содержаться пропуски ударений в 1-й стопе как в стихотворениях Христос или На сретение победителя, свободителя

${ }^{9}$ С. Я. Ляпин, К демифологизации ритмики русского четьрехстопного ямба (преимущественно на материале одического стиха Державина), «Philologica» 1997, т. 4, № 8/10, c. 307-322. 
и примирителя...). Отметим любовь поэта к пиррихию в 3-й стопе Я4: таких схем - большинство, что напоминает о схеме, выделявшейся Гаспаровым в качестве доминирующей (подчеркнем, что пиррихии, «узаконенные» в русской поэзии после воцарения Елизаветы Петровны ${ }^{10}$, активно используются Державиным в пятом томе и не воспринимаются как что-то необычное).

Также нельзя не обратить внимание на то, что во всем пятом томе у Державина нет строф, которые были бы тождественны с точки зрения метрических схем. Нечто подобное встречается в одной из последних строф Царь-Девищы («Заскрыпели двери ржавы / Оружейниц древних лет, / Воспрянули мужи славы / И среди пустынных мест» $\left.{ }^{11}\right)$, где имеется пропуск ударения на каждой 1-й стопе, в остальных стопах метрическое и фактическое ударения совпадают (выбивается слово «среди», фонетически примыкающее к следующему слову). В нескольких других строфах этого стихотворения метрическая идентичность строк не бесспорна. В других стихотворениях встречаются небольшие части строф (два-три стиха), в которых повторяется одна и та же схема, однако ни одна строфа не написана полностью одинаково.

Нередко у Державина встречаются сверхсхемные ударения. Почти всегда это непосредственно связано с содержанием текста. В стихотворении Христос встречаем, например, такой стих: «Кто Ты? - вспять Иордан бежал» ${ }^{12}$. Здесь невозможно определить только с помощью фонетических законов, какое из двух первых односложных слов несет главное ударение, поскольку с точки зрения семантики текста одинаково важны оба слова, к тому же это анафора, с которой начинаются семь строф. Вместе со следующим словом вспять образуется три идущих подряд ударения. Ту же картину можно наблюдать и в конце стиха: «И чрез пример явил сей Свой» ${ }^{13}$, где каждый из трех слогов в конце строки имеет собственное ударение. Аналогичная ситуация в стихе «Се, что есть Сый, что есть Христос» ${ }^{14}$ : каждое из идущих подряд шести односложных слов несет собственное ударение (можно сказать, что слово что «перетягивает» на себя ударение со слова ecmb, но это невозможно определить однозначно, поскольку с точки зрения смысла текста и его построения важно каждое из этих слов). В итоге из восьми слогов стиха семь являются ударными.

${ }^{10}$ М. И. Шапир, У истоков русского четырёхстопного ямба: генезис и эволюиия ритма (Соицолингвистика стиха раннего Ломоносова), [в:] он же, Universum versus: Язык - стих - смысл в русской поэзии XVIII-XX веков, Москва: Языки русской культуры 2000, кн. 1, с. 131.

${ }^{11}$ Г. Р. Державин, Сочинения..., с. 187.

12 Там же, с. 10.

13 Там же, с. 18.

14 Там же, с. 16. 
Нагромождение сверхсхемных ударений может быть тесно связано с сюжетом стихотворения. Например, в Проблеске есть два следующих стиха: «Подобно путник как сверх вод, сквозь лес, в мрак нощи / Зрит проблеск от луны» ${ }^{15}$. Трудность прохождения пути и мрачность обстановки подчеркиваются фонетически.

В некоторых случаях невозможно утверждать, что дополнительное ударение на слове вызвано необходимостью смыслового акцента. В стихотворении На отбытие... Николая Павловича и Михаила Павловича встречаем стихи: «И будут все благословенны / Шаги стоп ваших в сем пути» ${ }^{16}$. Односложное полнозначное слово стоп несет на себе дополнительное ударение, однако нельзя говорить о семантической функции этого ударения, скорее о том, что нужное с точки зрения повествования слово потребовало постановки «лишнего» ударения.

Отметим также случаи неоднократного использования в книге разрядки, с помощью которой подчеркиваются особо значимые слова. Эти mы, тобой и др. в стихотворениях, относящихся к царю, не несли бы на себе ударений, если бы не было такого графического оформления. В книгу включен целый ряд стихотворений, оформленных подобным образом, все они связаны с войной 1812 г. Тот же прием встречается и в стихотворениях На отбытие... Николая Павловича и Михаила Павловича, а также в Гимне, однако в них такая графика не влияет на произношение.

Встречаются также случаи, когда невозможно с уверенностью говорить о том, пиррихий ли перед читателем или «обычная» стопа, есть ли в стихе сверхсхемное ударение или нет. В этих случаях одинаково справедливы обе точки зрения как не противоречащие тексту. Здесь корректно говорить о вариативности прочтения, поскольку оно зависит от расстановки логических ударений. Например, стихотворение Упование на защиту Божию можно прочитать как диалог человека с Богом с четкой оппозицией в тексте небесного и земного. Тогда стихотворение будет насыщено дополнительными ударениями. Однако его можно рассматривать и как восхваление Бога, в котором человек (он же - «повествователь» в стихотворении) не является важным героем. Тогда это будет не диалог, а обращение к Богу, и все слова, относящиеся к человеку (ко мне, мой, меня и т. д.) не будут нести ударение (более того - текст станет наполненным пиррихиями). Оба варианта равно допустимы с точки зрения фонетических законов и семантики текста.

Заметим также, что поэт любит использовать двукорневые слова, имеющие «полуударение». Разумеется, в этом случае нельзя говорить

\footnotetext{
15 Там же, с. 79.

16 Там же, с. 214.
} 
о наличии двух ударений в слове, но такой случай, на наш взгляд, отличается и от «обычной» стопы, и от пиррихия. Примером могут служить стихи из Шествия по Волхову...: «Разноцветны по судам», «К камнетесанным брегам» ${ }^{17}$ и др.

Примеры переакцентуации в пятом томе относительно редки (например, в Истине: «Всех неумытнаго Судьи» ${ }^{18}$, в стихотворении Христос: «Бледн, бездыханен, мертв! - Кто ж Ты?», «Слить с невозможностью возможность?» ${ }^{19}$, в стихотворении K Каллиопе: «Всем населяющим вершины Ахероний» ${ }^{20}$ и др.) и не образуют тенденции.

Как было замечено ранее, Державин не предпочитает какую-либо одну модель Я4 другим. Это характерно и для других размеров, чьи схемы отличаются разнообразием. Отсутствуют предпочтения и в пропусках метрических ударений на определенных позициях. Можно отметить только ослабленность первой стопы в хореических строках, что объясняется не волей автора, а синтаксическим строением фразы: например, поэт любит «продолжать» повествование из одной строфы в другую и начинать строки с союза «и», на котором, разумеется, не будет фактического ударения.

Если говорить не о ямбических схемах, то любопытно использование трибрахиев среди стоп дактиля в стихотворении На покорение Парижа. Это объясняется отмеченным выше тяготением поэта к перечислительным конструкциям. Произведение содержит «припевы», размер которых можно определять как Дк2 с усеченной до ударного слога 2-й стопой, а можно как хореямб (кроме стиха «Сверг злость Ты душой», содержащего четыре ударения на пять слогов, что во втором случае можно трактовать как несколько неуклюжий хореямб, в который добавлен дополнительный слог).

По-настоящему необычной выглядит схема стихотворения Воцарение Правды. Это единственное произведение в книге, в котором есть регулярная переменная анакруза. Произведение написано амфибрахием, все строки, кроме 5-й в каждой строфе, - Амф2, 5-я строка - Амф3. При этом все строки, кроме 5-й, имеют стандартную для амфибрахия односложную анакрузу, а 5-я строка - нулевую. Благодаря этому складывается ощущение, будто в текст встроена строка дактиля, что создает эффект метрического разнообразия. Любопытно, что в 4-й строфе 1-я стопа этой выбивающейся из ряда других строк является трибрахием («И возгласит, что правдивы» ${ }^{21}$ ) и придает тексту необычное звучание.

\footnotetext{
${ }^{17}$ Г. П. Державни, Сочинения..., с. 157.

18 Там же, с. 5.

19 Там же, с. 11.

20 Там же, с. 197.

21 Там же, с. 40.
} 
Несколько раз Державин имитирует античные размеры, но то, что у него получается, не похоже ни на один из размеров, которыми в русской поэзии было принято имитировать античную метрику. Так построены К Бахусу и Полигимнии. Если в первом стихотворении можно уловить приметы русского гекзаметра, то во втором мы имеем дело с ритмическим представлением Державина о том, как должно звучать «античное» стихотворение. Поэт словно стилизует размер под античный, но у него получается «державинская версия» античности. Здесь можно видеть строки, похожие на дактиль, амфибрахий и анапест, метр некоторых строк напоминает тактовик, причем общее количество слогов в таких стихах бессистемно колеблется (7-10), количество ударных слогов также неодинаково. Больше этот размер не встречается в книге нигде.

Стихотворение Державина о поэте и поэзии написано весьма прихотливо и с точки зрения строфики - семистрочными полурифмованными строфами, АБАБХxx ВГВГХХर ДЕДЕХХх ЖЗЖЗХхx ИйИйХxx КлКлХхХ. Первые четыре строки в каждой строфе имеют перекрестную рифмовку, в четырех строфах из шести клаузулы женские, а в двух последних - чередование женских и мужских клаузул. В трех холостых стихах рисунок клаузул повторяется дважды, однако эти строфы отдалены друг от друга (1-я и 4-я; 2-я, 3-я и 5-я строфы), кроме того, 5-я строфа содержит в зарифмованной части чередование клаузул, что создает впечатление весьма разнообразно написанного текста. Схема же холостых стихов в последней строфе не повторяется больше нигде. Эта строфа, образующая смысловой центр стихотворения и пуантированная в сборнике финальным стихом «Буду я, буду бессмертен!» ${ }^{22}$, по-видимому, усложнена автором сознательно.

Подводя итог, можно сказать, что анализ метрико-строфического репертуара позднего Державина позволяет увидеть поэта как настоящего старого мастера, который помнит о вопросах версификации, избегает однообразия, ищет новые размеры, умело выстраивает композицию сборника в том числе с учетом стиховых особенностей составляющих его текстов.

\section{References}

Altshuller, Mark G. Oratoriya 'Tselenie Saula' v sisteme pozdnei liriki Derzhavina. In: XVIII vek. Vol. 21: Pamiati Pavla Naumovicha Berkova (1896-1969), ed. N. D. Kochetkova. SanktPeterburg: Nauka, 1999: 269, 281.

Brown, John. The Cure of Saul, a sacred ode. London: L. Davis and C. Reymers, 1763.

Derzhavin, Gavriil R. Sochineniya Derzhavina. Vol. 5. Sankt-Peterburg: V Tip. V. Plavilshchikova, 1816.

22 Там же, с. 238. 
Gasparov, Mikhail L. Ocherk istorii russkogo stikha. Moskva: Fortuna Limited, 2000.

Korovin, Vladimir L. "Derzhavin i 1812 god: O smysle i kompozitsii ‘Gimna liroepicheskogo na prognanie frantsuzov iz Otechestva”. Izvestiya Rossiiskoi akademii nauk. Seriya literatury i yazyka. Vol. 71, No. 6 (2012): 42-52.

Lyapin, Sergei Ye. "K demifologizatsii ritmiki russkogo chetyrekhstopnogo yamba (preimushchestvenno na materiale odicheskogo stikha Derzhavina)". Philologica. Vol. 4, No. 8/10 (1997): 307-322.

Ostolopov, Nikolai F. Klyuch $k$ sochineniyam Derzhavina: $S$ kratkim opisaniem zhizni sego znamenitogo poeta. Sankt-Peterburg: V tip. Iv. Glazunova, 1822.

Shapir, Maksim I. U istokov russkogo chetyrekhstopnogo iamba: genezis i evolyutsiya ritma (Sotsiolingvistika stikha rannego Lomonosova). In: Universum versus: Yazyk - stikh - smysl v russkoi poezii XVIII-XX vekov. Vol. 1. Moskva: Yazyki russkoi kultury, 2000: 131-161.

\footnotetext{
\begin{tabular}{|c|l|}
\hline cc) Creative & $\begin{array}{l}\text { (c) by the author, licensee Lodz University - Lodz University Press, Lodz, } \\
\text { Poland. This article is an open access article distributed under the terms and } \\
\text { conditions of the Creative Commons Attribution license CC-BY-NC-ND } 4.0 \\
\text { (https://creativecommons.org/licenses/by-nc-nd/4.0/) }\end{array}$
\end{tabular}
} 